\title{
СОПОСТАВИТЕЛЬНЫЙ АНАЛИЗ СОВРЕМЕННЫХ РОССИЙСКИХ И ЗАРУБЕЖНЫХ КЛАССИФИКАЦИЙ ПРЕДПРИНИМАТЕЛЬСКИХ РИСКОВ
}

Аннотация. В настоящей статье, подготовленной по итогам прохождения курса «Управление системами безопасности бизнеса», рассматриваются российские и зарубежные классификации предпринимательских рисков. Автор, используя метод сравнительного анализа, рассматривает подходы к понятию предпринимательского риска в российской и зарубежной науке, а затем сопоставляет некоторые классификации этих рисков, выявляя и анализируя присущче им особенности. Новизна статьи состоит в том, что в современных условиях это первая попытка сопоставления различных по своим подходам отечественной и зарубежных школ риск-менеджмента. В настоящей рассматриваются различные подходы к пониманию предпринимательского риска, как российских, так и зарубежных исследователей, а также различные системы классификации этих рисков. В заключении отмечается, что российские и зарубежные системы классификации рисков (также как и подходы к пониманию предпринимательского риска как такового) имеют значительное сходство, но вместе с тем обладают своей специффикой. Вероятно, что эта специифика отражает особенности и проблемные стороны той или иной среды, в которой действует бизнес.

Ключевые слова: предпринимательство, безопасность предпринимательской деятельности, риск-менеджмент, предпринимательский риск, классификация предпринимательских рисков, мера возможных перемен, неблагоприятный исход, бизнес, анализ, контроль.

\section{Введение}

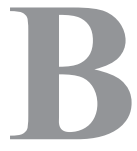
настоящее время предпринимательство как особая форма ведения бизнеса играет очень важную роль в условиях стремительного развития рыночных отношений, глобализации. Нередко предпринимательство называют движущей силой экономики, и это справедливо, ведь бизнес всегда связан с созданием новых рабочих мест, стимулированием спроса и предложения, технологическим прогрессом, а, следовательно, и экономическим ростом в целом.

Однако, вместе с тем стоит понимать, что любая предпринимательская деятельность вынуждена развиваться в условиях серьёзных рисков, как со стороны внешних факторов, так и внутренних. Это связано, в первую очередь, с тем, что рынок по природе своей несовершенен - недостаточное количество информации, регулярные социально-экономические и политические изменения, которые также оказывают непосредственное влияние на бизнес, особенности человеческих факторов и т.д.

В этих условиях появляется серьёзная необходимость в борьбе с неопределённостью, контроле над рисками и эффективном их управлении. Именно для того, чтобы облегчить выполнение этих задач, многие 
ученые занимаются тщательным изучением рисков, их объяснением и систематизацией.

Если говорить о сравнении российского и зарубежного опыта в этом направлении, то стоит сперва отметить то, что предпринимательство как форма организации и ведения бизнеса является довольно новым опытом для российской экономики. В отличие от крупных европейский держав и США, где расцвет предпринимательства в его более менее современном понимании происходил на протяжении 18-19x веков, в России эта форма получила признание и распространение лишь в конце 20-го столетия. Отсюда можно предположить, что даже при наличии каких-то общих рисков, актуальных для любого хозяйственного субъекта, наверняка существуют и специфические угрозы, свойственные для тех или иных социальных, экономических, политических и исторических условий. Это предположение подтверждается и тем фактом, что многие исследователи до сих пор не могут найти согласия относительно определения предпринимательских рисков и их классификации.

Таким образом, попытка выявить и объяснить существующие различия в системах классификации рисковпредставляется весьма интересной.

\section{РОССИЙСкИЙ ОПЫТ}

\section{Определение предпринимательского риска}

Прежде чем анализировать классификации необходимо посмотреть на то, как те или иные исследователи понимают предпринимательский риск.

Как уже было сказано выше, на сегодняшней день не существует единственного и четкого определения на этот счёт. Кто-то связывает риск с вероятностью потери или недополучения доходов, кто-то с наступлением неожиданных последствий управленческих решений, кто-то с ущербом и т. д. Ниже представлены некоторые определения, предлагаемые отечественными исследователями:

Предпринимательский риск- это:

- «... возможность наступления (опасность возникновения) неблагоприятного события, в результате которого субъект, принявший решение, направленное на достижение поставленной цели, теряет полностью или частично свои ресурсы, недополучает ожидаемый доход или несет не предусмотренные замыслом дополнительные материальные и финансовые расходы»(Сmуnаовк В. С., Токаренко Г. С.- [12])

- «... характеристика деятельности, осуществляемой в ситуации большей или меньшей неопределенности, обусловленной недостаточностью информации, когда предприниматель, будучи не в состоянии однозначно установить тенденции и последствия развития сложившейся ситуации, оказывается перед необходимостью разработки альтернативных вариантов решений и последующего выбора из того, которое ему представляется наиболее разумным, сопряжённым с вероятностью наименьших потерь (ущерба, проигрыша)» (Ахундов B. M., Соболь А.И.- [2])

- «... экономическая категория, количественно (да и качественно) выражающаяся внеопределённости исхода намеченной предпринимательской деятельности, отражающей степень неуспеха (или/и успеха) деятельности предпринимателя (фирмы) по сравнению с заранее планируемыми результатами» (Лапуста М. Г.[8])

- «... опасность возникновения неблагоприятных последствий (имущественно- 


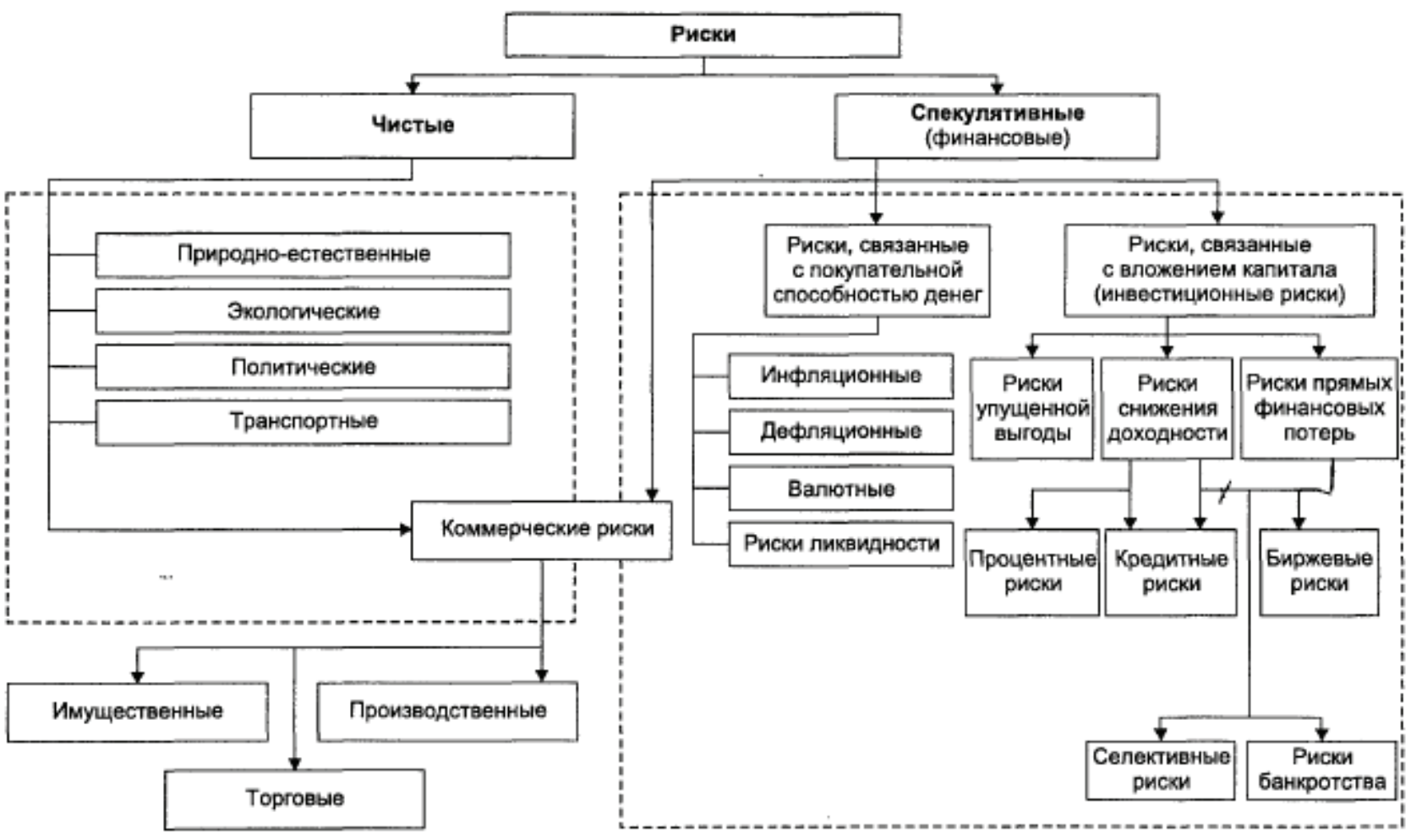

Рис. 1. Иерархическая система классификации рисков Балабанова И. Т.

го или личного характера), относительно которых неизвестно, наступят они или нет» (Абчук B. A.- [1])

- «... неопределенность в отношении возможных потерь на пути к цели»

(Вишняков Е.Д., Радаев Н. Н.- [5])

- «... это экономическая категория. Как экономическая категория он представляет собой возможность совершения события, которое может повлечь за собой три экономических результата: отрицательный (проигрыш, ущерб, убыток); нулевой; положительный (выигрыш, выгода, прибыль)». (Балабанов И. Т.- [3]) Уже на основании предложенных вариантов определений предпринимательского риска можно сделать вывод о том, что за некоторым исключением российские исследователи связывают его, как правило, с опасностью возникновения неблагоприятных последствий, которые могут выражаться в потере дохода, ресурсов или необходимости дополнительных вложений, а также с неопределённостью ситуащии, в которой принимаются решения. Также можно добавить, что часто для характеристики риска используется понятие «неопределённость», что можно трактовать разным образом. С одной стороны, можно считать, чтокак экономическая категория неопределённость в широком смысле воспринимается российскими исследователями полностью тождественнойриску, наступление событий при котором, соответственно, вероятно и определено. Однако, с другой стороны, можно также предположить, что данное сведение риска к неопределённости свидетельствует как раз об обратном - о сложности какогото его вероятностного расчета, управления и контроля. И тогда в российской практике риск предстаёт чем-то не только неизбежным, но и неподвластным. 


\section{Системы классификации рисков}

Относительно классификации и систематизации рисков также существует различные подходы. Некоторые современные исследователи (например, Панягина A. B.- [10]) выделяют два основных подхода к классификации - предметный, когда внимание уделяется конкретному содержанию, и так называемый управленческий, когда риски анализируются с точки зрения источника и этапа возникновения.

В настоящей работе будут рассмотрены, в первую очередь, предметные классификации рисков, поскольку именно на уровне них можно проследить различия российского и зарубежного опыта.

В качестве примеров российских классификаций рассмотрим две, касающиеся коммерческой и производственной деятельности соответственно.Ниже представлена классификация Балабанова И.Т., которая считается наиболее распространённой, и в которой риски расположены в иерархическом порядке (рис. 1).

Как можно увидеть, Балабанов И. Т. на первоначальном этапе разделяет риски на чистые (нефинансовые, вызванные внешними факторами, практически неуправляемые) и спекулятивные (связанные непосредственно с финансовыми потерями такими, как падение прибыли, дохода и т.п.). Каждая из этих групп имеет свои составляющие, причем коммерческие риски, как представлено на схеме, включаются как в чистые, так и спекулятивные, и этот момент необходимо пояснить. Чистые коммерческие риски включают следующие:

- имущественные (и здесь имеется в виду потеря имущества по причине кражи, поломки и т.п.)

- производственные (имеются в виду убытки от остановки производства, но именно те, что не выражаются напрямую в финансовых показателя - порча или повреждения транспорта, материалов, оборудования и т.п.)

- торговые (задержка платежей. недопоставка товара и т. п.)

Если же говоря о рисках, подразумеваются финансовые потери в ходе коммерческой сделки, то эти риски входя в группу коммерческих, но являются при этом спекулятивными.

Также имеет смысл пояснить, что такое селективные риски - это риски, связанные с выбором неправильной структуры вложения капитала при формировании инвестиционного портфеля.

Данная система классификации свойственнакоммерческим и финансовым структурам, именно поэтому риски в ней организованы именно таким образом с разделением на финансовые и нефинансовые.

Если же в качестве объекта исследования выступает производственная структура, то здесь имеет место несколько иная система классификации, представленная на Рис.2 (Клейнер Г. Б., Качалов Р. М., Тамбовиев В. A.- [6]).

Здесь уже на первом этапе риски делятся на внешние (не связанные непосредственно с деятельностью предприятия) и внутренние (связанные с деятельностью предприятия). Как видно из схемы внешние риски в большинстве дублируют чистые риски из прошлой схемы, однако вместо природно-естественных рисков появляются социально-экономические, а также добавляются научно-технические. Это добавление весьма объяснимо, учитывая специфику работы производственных предприятий.

В целом по классификации можно отметить, что некоторые риски идентичны рискам классификации Балабанова И. Т., однако финансовые угрозы практически отсутствуют, а большее внимание уделяется рискам технического, технологического и аварийного характера. 


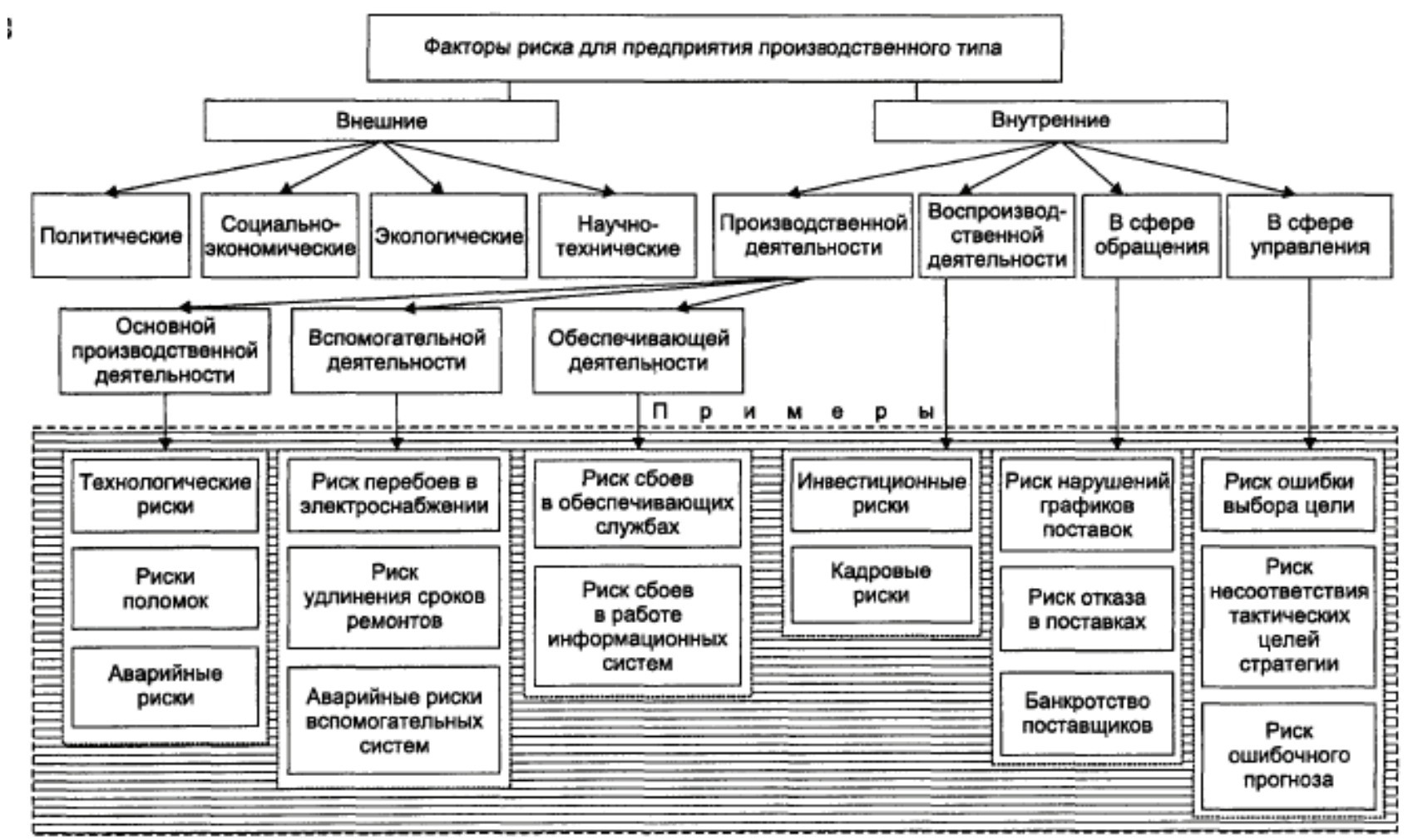

Рис. 2 Иерархическая система классификачии рисков Клейнера Г. Б. Качалова Р. М., Тамбовиева В.А.

\section{ЗАРУБЕЖНЫЙ ОПЫТ}

\section{Определение предпринимательского риска и его суть}

Теперь рассмотрим определения предпринимательского риска, предлагаемые зарубежными исследователями:

Предпринимательский риск - это:

- «... скорее, выбор, нежели жребий. Вероятность (угроза) потери предприятием части своих ресурсов, недополучения доходов или появления дополнительных расходов в результате осуществления определенной производственной или хозяйственной деятельности» (Бернстайн, 2000)

- «... измеримая неопределённость» (Haйm Ф.)

- «... мера возможных перемен в стоимости портфеля инвестиций, ко- торые будут результатами различия обстановки сегодня и в некоторой временной точке будущего» (Дембо Р., Фримен А.)

- «... возможность того, что случится нечто нежелательное: кража, крах фирмы, появление нового конкурента, увечье, повреждение, обесценивание, смерть и многое другое»

- «... вариация исходов, которые могут произойти в течение определённой ситуации» (Вильямс С. А., Хейнс Р. М.)

- вероятность неблагоприятного исхода, когда компания не получает ожидаемого результата (Лис Ф.- [15])

На основе предложенных определений можно заключить, что в зарубежном опыте риск также часто связывают с возможностью неблагоприятных исходов, однако вместе с тем сравнительно часто встречаются варианты, когда риск воспринимается не как 


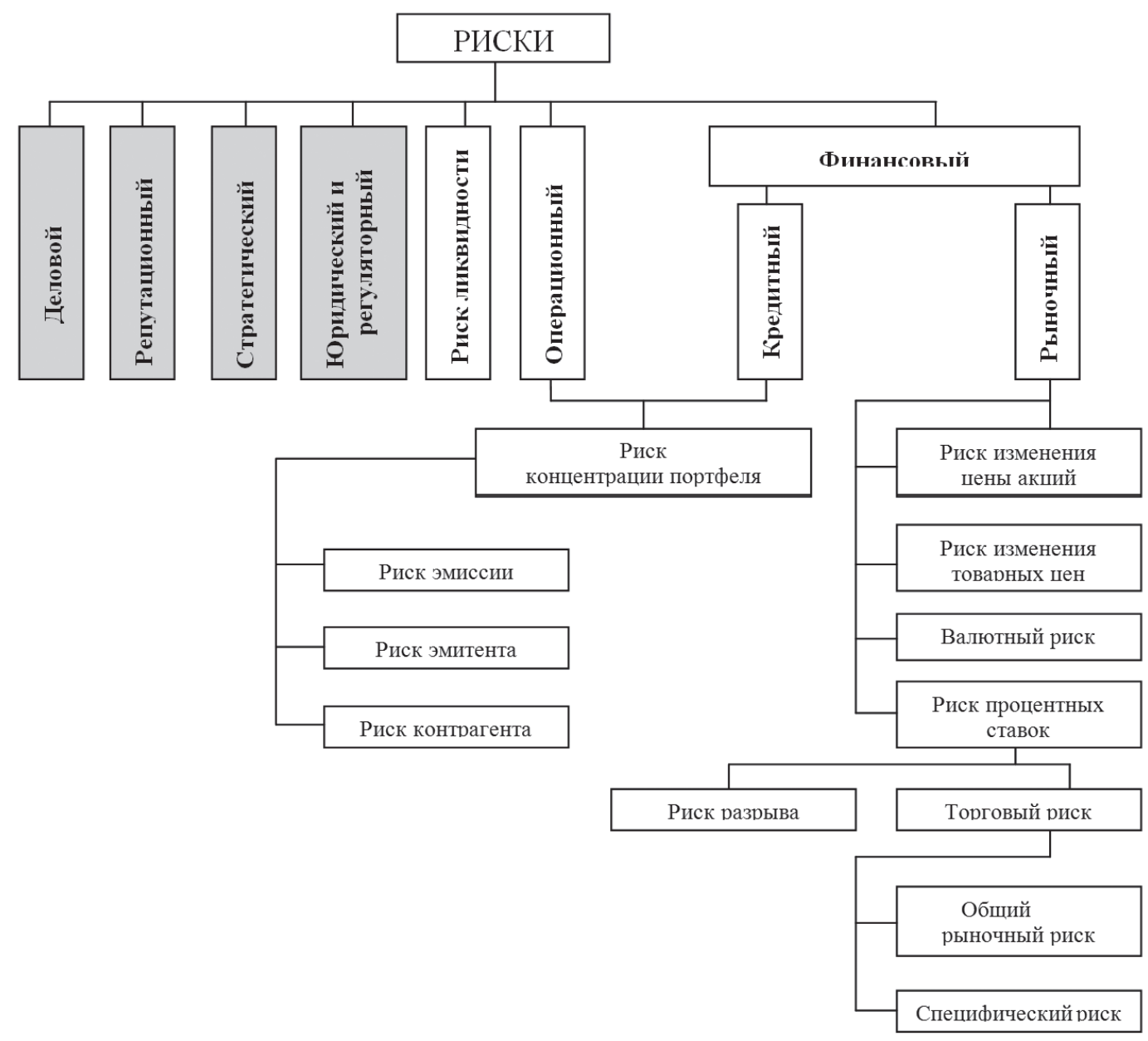

Рис. 3 Система классификации рисков Круи М., Галай Д. и Марком Р.

однозначная угроза, а как возможность перемен или различных исходов. Более того, возможность особенно благоприятных событий, иногда рассматривается тоже как риск [7].

Ещё одно общее отличие зарубежных определений риска от российских в том, что иностранные ученые в большинстве своём предпочитают все же разделять понятия «неопределённость» и «риск» в соответствии со степенью их оценки, и эту возможность измерения, предугадывания они подчеркивают в предлагаемых определениях. Иными словами, можно предположить, что риск, в отличие от российских коллег, ими воспринимается как нечто управляемое и контролируемое.

\section{Системы классификации рисков}

Что касается зарубежных систем классификации рисков, то они несколько отличаются. В качестве примера рассмотрим систему, предложенную Круи М., Галай Д. и Марком Р. [16] (Рис. 3)

Глядя на представленную систему можно заметить, что какие-то позиции в той или иной степени совпадают с российской классификацией, однако также есть и существенные отличия. Главное, что бросается в глаза - это то, что природно-естественные, экологические, политические, транспортные и часть коммерческих рисков были исключены, вместо чего появились деловой, репутационный, стратегический, юридический и регуляторный риски, 


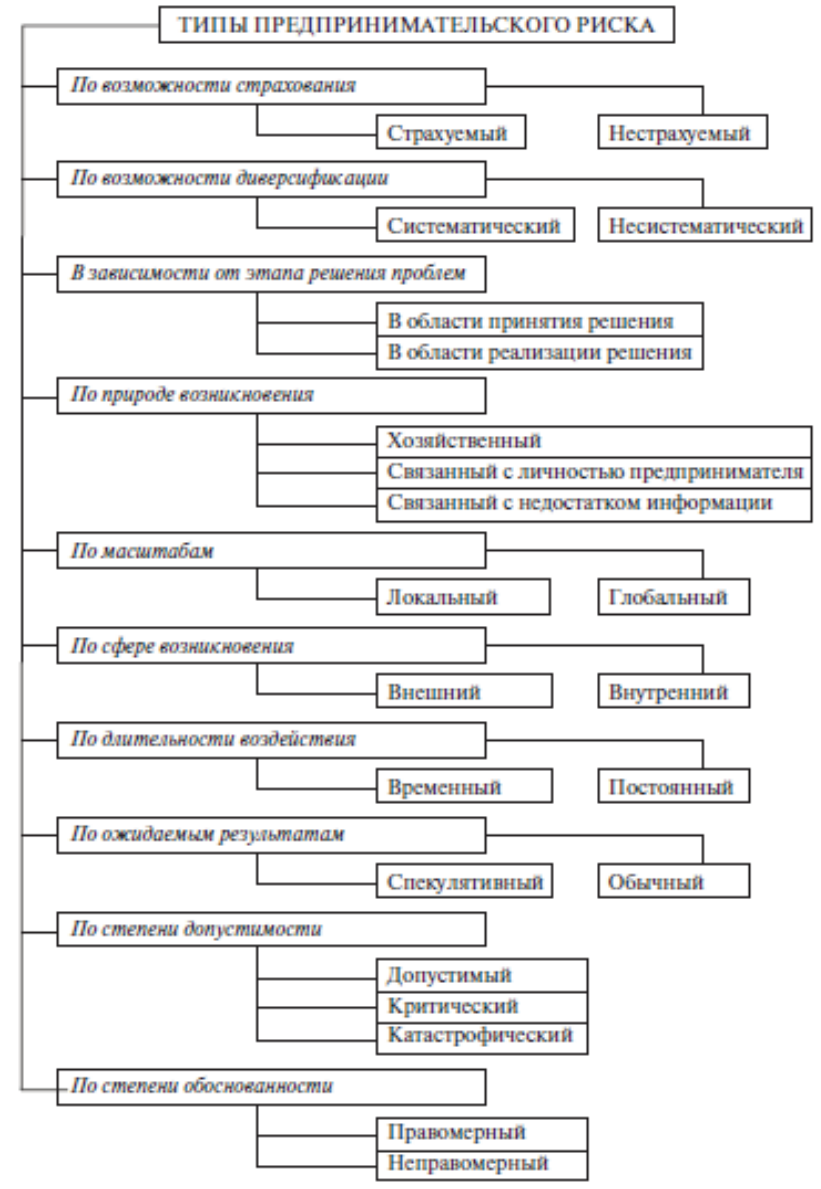

Рис. 4. Пример «управленческой классификации»

которые в российской модели представлены не были. Ниже представлена краткая характеристика каждого из этих видов рисков:

- Юридический и регуляторный риски возможны в ситуации, когда допущены ошибки правового характера при составлении договоров, организации сделок и т.п.

- Репутационный риск - весьма субъективен в отношении его оценки, наиболее вероятен в среде финансовых институтов, поскольку там вопрос касается конфиденциальности всех заинтересованных лиц (включение данного риска в систему произошло после ряда конкретных неприятных случаев и скандалов, связанных с ведением бухгалтерской отчетности в Соединённых штатах в конце 90-х)
- Стратегический риск - риск, связанный с осуществлением значительных инвестиций, имеющий долгосрочный характер, но при этом не имеющих гарантии успеха и прибыльности.

- Деловой риск - любой риск, связанный с ситуациями на рынке - спросом, ценой, конъюнктурой рынка и т. п.

Также можно отметить и то, что значительную долю рисков представленных в схеме, составляют риски, связанные с ценными бумагами, что также отличает зарубежную классификацию от российских.

\section{Общий подход}

Выше были рассмотрены так называемые предметные классификации, однако, как уже было отмечено, существуют также и управленческие классификации, которые рассматривают риски с позиции источников их возникновения. Если сравнивать российские и зарубежные классификации, тот как раз эти, на уровне управленческих систем, носят идентичный характер. Вероятно, это связано с тем, что они более комплексны и универсальны в том смысле, что используются на последующем этапе после выявления рисков, уже при формировании общей стратегии риск-менеджмента. Пример такой классификации представлен на Рис. 4.

\section{Заключение}

Итак, в настоящей статье были рассмотрены различные подходы к пониманию предпринимательского риска, как российских, так и зарубежных исследователей, а также различные системы классификации этих рисков.

В качестве итога можно ещё раз отметить, что российские и зарубежные системы 
классификации рисков (также как и подходы к пониманию предпринимательского риска как такового) имеют значительное сходство, но вместе с тем обладают своей спецификой. Вероятно, что эта специфика отражает особенности и проблемные стороны той или иной среды, в которой действует бизнес.

Например, рассмотрев классификацию российских исследователей, можно увидеть, что у нас существенное положение занимают политические, социально-экономические, коммерческие риски. Это в какой-то степени, может свидетельствовать о сравнительной нестабильности и ненадежности экономической среды, невозможности её контролировать и управлять ею в той степени, в какой это необходимо для более успешного функционирования бизнеса.

В производственном же секторе у нас отдельно выделяются риски технические, управленческие, кадровые, и их также, возможно, следует воспринимать как определённые «индикаторы» проблемн
Что касается зарубежной системы, то там внешним рискам уделяется меньшее внимание. Это не значит, что их не существует, просто внимание исследователей в первую очередь направлено на управление внутренними рисками. Возможно, это связано с тем, что именно внутренние риски менеджер в состоянии контролировать и избегать, в то время как внешние риски практически не поддаются управлению в силу своей природы. Отсюда можно сделать предположение, что зарубежные исследователи более практичны в своём подходе. И в качестве особенности ещё раз хочется отметить, что в зарубежной системе отдельно выделен репутационный риск, который полностью отсутствует в нашей классификации, и значительное внимание уделено рискам, связанным с ценными бумагами. Эти особенности в какой-то степени, возможно, тоже можно считать особенностями зарубежной экономической среды. ых областей.

\section{Библиография}

1. Абчук, В.А. Риски в бизнесе, менеджменте и маркетинге / В. А. Абчук.- СПб.: Изд-во Михайлова В.А, 2006.

2. Ахундов В. М., Соболь А.И. Финансовый риск. М., 2000

3. Балабанов И. Т. Риск-менеджмент. М., 1996.

4. Балдин К. В. Воробьев С. Н. Риск-менеджмент: Учебное пособие.- М.: Гардарики, 2005.

5. Вишняков Е. Д., Радаев Н. Н. Общая теория рисков: учеб. пособие для студ. высш. учеб. заведений / Я. Д. Вишняков, Н. Н. Радаев.- М.: Издательский центр «Академия», 2007.

6. Клейнер Г. Б., Тамбовцев В. А., Качалов Р. М. Предприятие в нестабильной экономической среде: риски, стратегия, безопасность.- М.: Экономика, 1997.

7. Кривуля П. В. Шурхно И.В. Обзор определений категории «риск» и их сравнительное моделирование на основе семантических сетей.

8. Лапуста М.Г. Предпринимательство: Учебник.- М.: ИНФРА-М, 2008.— с. 496

9. Омарова Н. Ю., Бедовая Л. В. Проблемы классификации предпринимательских рисков в условиях современности// Экономические науки. Фундаментальные исследования-№ 11, 2012

10. Панягина А. Е. Походы к пониманию и классификации рисков // Современная экономика: проблемы, тенденции, перспективы, № 6, 2012.

11. Сидельников Ю. В., Танасова А.С. Риск в современном обществе. Концептуальная интерпретация в ситуации выбора, 2011 
12. Ступаков В. С., Токаренко Г. С. Риск-менеджмент: Учеб. пособие.- М.: «Финансы и статистика», М. 2005

13. Тимофеев А. В. Предпринимательство - движущая сила качественных сдвигов в эпохи перемен// Экономическая теория. Экономические науки - 10 (71) - 2010

14. Тэмпан Л. Н. Риски в экономике: Учеб. пособие для вузов/ Под ред. проф В. А. Швандара.М.: ЮНИТИ-ДАНА, 2002.

15. Управление современной компанией: Учебник / Под ред. проф. Б. Мильнера, Ф. Лиса.М.: ИНФРА-М, 2001

\section{References (transliterated)}

1. Abchuk, V. A. Riski v biznese, menedzhmente i marketinge / V. A. Abchuk.- SPb.: Izd-vo Mikhailova V.A, 2006.

2. Akhundov V. M., Sobol» A. I. Finansovyi risk. M., 2000

3. Balabanov I. T. Risk-menedzhment. M., 1996.

4. Baldin K. V. Vorob'ev S. N. Risk-menedzhment: Uchebnoe posobie.- M.: Gardariki, 2005.

5. Vishnyakov E. D., Radaev N. N. Obshchaya teoriya riskov: ucheb. posobie dlya stud. vyssh. ucheb. zavedenii / Ya.D. Vishnyakov, N. N. Radaev.— M.: Izdatel'skii tsentr «Akademiya», 2007.

6. Kleiner G. B., Tambovtsev V. A., Kachalov R. M. Predpriyatie v nestabil'noi ekonomicheskoi srede: riski, strategiya, bezopasnost».- M.: Ekonomika, 1997.

7. Krivulya P. V. Shurkhno I. V. Obzor opredelenii kategorii «risk» i ikh sravnitel'noe modelirovanie na osnove semanticheskikh setei.

8. Lapusta M. G. Predprinimatel'stvo: Uchebnik.— M.: INFRA-M, 2008.— s. 496

9. Omarova N. Yu., Bedovaya L. V. Problemy klassifikatsii predprinimatel'skikh riskov v usloviyakh sovremennosti// Ekonomicheskie nauki. Fundamental'nye issledovaniya-№ 11, 2012

10. Panyagina A.E. Pokhody k ponimaniyu i klassifikatsii riskov // Sovremennaya ekonomika: problemy, tendentsii, perspektivy, № 6, 2012.

11. Sidel'nikov Yu.V., Tanasova A. S. Risk v sovremennom obshchestve. Kontseptual'naya interpretatsiya $\mathrm{v}$ situatsii vybora, 2011

12. Stupakov V. S., Tokarenko G. S. Risk-menedzhment: Ucheb. posobie.- M.: «Finansy i statistika», M. 2005

13. Timofeev A. V. Predprinimatel'stvo - dvizhushchaya sila kachestvennykh sdvigov v epokhi peremen// Ekonomicheskaya teoriya. Ekonomicheskie nauki - 10 (71) - 2010

14. Tempan L. N. Riski v ekonomike: Ucheb. posobie dlya vuzov/ Pod red. prof V. A. Shvandara.M.: YuNITI-DANA, 2002.

15. Upravlenie sovremennoi kompaniei: Uchebnik / Pod red. prof. B. Mil'nera, F. Lisa.- M.: INFRA-M, 2001 